\title{
Synergism of a novel MCL-1 downregulator, acriflavine, with navitoclax (ABT-263) in triple-negative breast cancer, lung adenocarcinoma and glioblastoma multiforme
}

\author{
ANBOK LEE ${ }^{1 *}$, HYEON-OK JIN $^{2 *}$, MD. MASUDUL HAQUE ${ }^{3}$, HEE YEON KIM $^{1}$, HANA JUNG $^{3}$, \\ JIN HEE PARK ${ }^{3}$, ILHWAN KIM ${ }^{4}$, JOO YEON SONG ${ }^{5}$, HYE KYOUNG YOON ${ }^{6}$, HYOUNG KYU KIM ${ }^{7}$, \\ JIN $\mathrm{HAN}^{7}$, IN-CHUL PARK $^{8}, \mathrm{KWANG}$ SEOK KIM ${ }^{8 *}$ and SAE GWANG PARK ${ }^{3,9^{*}}$ \\ ${ }^{1}$ Department of Surgery, Busan Paik Hospital, College of Medicine, Inje University, Busan 47392; \\ ${ }^{2}$ KIRAMS Radiation Biobank, Korea Institute of Radiological and Medical Sciences, Seoul 01812; \\ ${ }^{3}$ Department of Microbiology and Immunology, College of Medicine, Inje University, Busan 47392; \\ ${ }^{4}$ Department of Internal Medicine, Division of Oncology, Haeundae Paik Hospital, College of Medicine, \\ Inje University, Busan 48108 ; ${ }^{5}$ Department of Pathology, Dongnam Institute of Radiological and Medical Sciences, \\ Busan 46033; ${ }^{6}$ Department of Pathology, Inje University, Busan $47392 ;{ }^{7}$ Cardiovascular and \\ Metabolic Disease Center, Smart Marine Therapeutic Center, College of Medicine, Inje University, \\ Busan 47397; ${ }^{8}$ Division of Radiation Biomedical Research, Korea Institute of Radiological and \\ Medical Sciences, Seoul 01812; ${ }^{9}$ Innovative Therapeutic Research Institute, \\ College of Medicine, Inje University, Busan 47397, Republic of Korea
}

Received April 29, 2021; Accepted September 27, 2021

DOI: 10.3892/ijo.2021.5292

\begin{abstract}
Myeloid cell leukemia sequence 1 (MCL-1), an anti-apoptotic B-cell lymphoma 2 (BCL-2) family molecule frequently amplified in various human cancer cells, is known to be critical for cancer cell survival. MCL-1 has been recognized as a target molecule for cancer treatment. While various agents have emerged as potential MCL-1 blockers, the present study presented acriflavine (ACF) as a novel MCL-1 inhibitor in triple-negative breast cancer (TNBC). Further evaluation of its treatment potential on lung adenocarcinoma and glioblastoma multiforme (GBM) was also investigated. The anticancer effect of ACF on TNBC cells was demonstrated when MDA-MB-231 and HS578T cells were treated with ACF. ACF significantly induced typical intrinsic apoptosis in TNBCs in
\end{abstract}

Correspondence to: Dr Sae Gwang Park, Department of Microbiology and Immunology, College of Medicine, Inje University, 75 Bokji-ro Street, Busan 47392, Republic of Korea

E-mail: micpsg@inje.ac.kr

Dr Kwang Seok Kim, Division of Radiation Biomedical Research, Korea Institute of Radiological and Medical Sciences, 75 Nowon-ro Street, Seoul 01812, Republic of Korea

E-mail: kskim@kirams.re.kr

*Contributed equally

Key words: acriflavine, navitoclax, myeloid cell leukemia sequence 1 downregulation, triple-negative breast cancer, drug resistance a dose- and time-dependent manner via MCL-1 downregulation. MCL-1 downregulation by ACF treatment was revealed at each phase of protein expression. Initially, transcriptional regulation via reverse transcription-quantitative PCR was validated. Then, post-translational regulation was explained by utilizing an inhibitor against protein biosynthesis and proteasome. Lastly, immunoprecipitation of ubiquitinated MCL-1 confirmed the post-translational downregulation of MCL-1. In addition, the synergistic treatment efficacy of ACF with the well-known MCL-1 inhibitor ABT-263 against the TNBC cells was explored [combination index $(\mathrm{CI})<1$ ]. Conjointly, the anticancer effect of ACF was assessed in GBM (U87, U251 and U343), and lung cancer (A549 and NCI-H69) cell lines as well, using immunoblotting, cytotoxicity assay and FACS. The effect of the combination treatment using ACF and ABT-263 was estimated in GBM (U87, U343 and U251), and non-small cell lung cancer (A549) cells likewise. The present study suggested a novel MCL-1 inhibitory function of ACF and the synergistic antitumor effect with ABT-263.

\section{Introduction}

While breast cancer is a preeminent threat to the healthcare of women worldwide, triple-negative breast cancer (TNBC) is the most notable subtype due to its incomparable aggressiveness. Currently, treatment for TNBC primarily relies only on systemic cytotoxic chemotherapy, with a rather unsatisfactory prognostic outcome (1). Therefore, effective therapy for TNBC is urgently required.

Apoptosis, programmed cell death, is an intrinsic phenomenon for normal embryonic development and tissue 
homeostasis. Dysregulation of apoptosis is a critical step in cancer pathogenesis and is one of the major barriers to effective cancer treatment $(2,3)$. The B-cell lymphoma 2 (BCL-2) protein family regulates the apoptosis pathway through mitochondrial outer membrane permeabilization, the cytosolic release of mitochondrial protein, cytochrome $c$, and caspase activation (4,5). Cancer cells resist apoptosis through various strategies, including increased expression of anti-apoptotic BCL-2 family proteins. The BCL-2 family includes anti-apoptotic members such as BCL-2, BCL-XL, BCL-W, as well as myeloid cell leukemia sequence 1 (MCL-1), and pro-apoptotic members such as BAX, BAK, and BH3-only (6).

MCL-1 has unique features among the BCL-2 family, including structure, function, and regulation (4). MCL-1 has a high affinity for pro-apoptotic BH3 peptides of BAX, BAK, BID, PUMA and NOXA compared with other BCL-2 anti-apoptotic family proteins (7). MCL-1 expression is quickly and readily induced by environmental stimuli including cytokines and growth factors unlike other proteins in the family such as BCL-2 and BCL-XL (8). MCL-1 is overexpressed in various human hematologic and solid cancers (7), and MCL-1 gene amplification has been observed in diverse cancers (9). MCL-1 is responsible for resistance to chemotherapeutic agents, and its high expression is associated with poor prognosis $(10,11)$. The resistance to navitoclax (ABT-263) and venetoclax (ABT-199) has been demonstrated to be linked to high expression levels of MCL-1. In numerous instances, this resistance could be overcome by treatment with agents that downregulate, destabilize, or inactivate MCL-1 (12-14). Thus, MCL-1 has recently been recognized as an emerging therapeutic target in cancer.

Acriflavine (ACF), a mixture of 3,6-diamino-10-methylacridinium chloride (trypaflavin) and 3,6-diaminoacridine (proflavine) has been used as an antimicrobial agent a century ago (15). Recently, its potential as an anticancer agent has been highlighted. The antitumor activity of ACF has been reported in various cancers, including colorectal, pancreas, and prostate (16-21). Its mechanism is still under investigation; however, HIF-1 inhibition is considered as the main anticancer mechanism.

In the present study, the anticancer activity of ACF on TNBC cells and its cell death mechanism were evaluated. Furthermore, the interaction of MCL-1 protein in TNBC cells during ACF-induced cancer apoptosis was revealed. The potential of MCL-1 downregulation by ACF as a breakthrough strategy against $\mathrm{BCL}-2$ inhibitor resistance was evaluated. Additionally, the therapeutic potential of ACF against non-small cell lung cancer (NSCLC) and glioblastoma multiforme (GBM) was demonstrated.

\section{Materials and methods}

Reagents and antibodies. ACF was purchased from Sigma-Aldrich; Merck KGaA. APC Annexin V Apoptosis Detection Kit was purchased from BioLegend, Inc (cat. no. 640930). APC anti-human IgG was purchased from BioLegend, Inc. (cat. no. 366906). ABT-263 was purchased from Santa Cruz Biotechnology, Inc. (cat. no. sc-207241). Monoclonal antibodies to detect MCL-1 (product no. 5453), GSK-3 $\beta$ (product no. 9315), phosphorylated (p)-GSK-3 $\beta$ (product no. 9323), GAPDH (product no. 2118) and polyclonal antibodies to detect p-MCL1 (product no. 4579), BCL-XL (product no. 2762), BCL-2 (product no. 2872), $\beta$-catenin (product no. 9562), cleaved PARP (product no. 9541), caspase-8 (product no. 9746), caspase-9 (product no. 9502), ubiquitin (product no. 3933), XAF1 (product no. 13805S) and XIAP (product no. 2042) were purchased from Cell Signaling Technology, Inc. Monoclonal antibody against $\beta$-actin (cat. no. A5316) was obtained from Sigma-Aldrich; Merck KGaA. Monoclonal antibodies to evaluate caspase-3 activation were purchased from Abcam (product code ab136812). MG-132 (product no. M7449), and cycloheximide (CHX; product no.C4859) were purchased from Sigma-Aldrich; Merck KGaA. Protein A/G PLUS-Agarose (cat. no. sc-2003) was purchased from Santa Cruz Biotechnology, Inc.

Cell line culture. The human cancer cell lines MDA-MB-231 (HTB-26), HS578T (HTB-126), HCC-70 (CRL-2315), A549 (CCL-185), and NCI-H69 (HTB-119) cells were purchased from the American Type Culture Collection (ATCC). U87 (glioblastoma of unknown origin), U343 and U251 cells were kindly received as a gift from Professor Jongsun Park (Department of Pharmacology, College of Medicine, Chungnam National University, South Korea). STR profiling was performed on all cell lines. All cells were cultured in Dulbecco's modified Eagle's medium (DMEM) or RPMI-1640 medium with $10 \%$ fetal bovine serum (FBS) (all from Cytiva) and $1 \%$ penicillin, and cultured at $37^{\circ} \mathrm{C}$ with $5 \% \mathrm{CO}_{2}$. Cells were routinely controlled to exclude mycoplasma contamination.

Determination of cell viability. The In Vitro Toxicology Assay Kit (product no. TOX6; Sigma-Aldrich; Merck $\mathrm{KGaA}$ ) was used to determine cellular viability. Briefly, cells $\left(0.5-2 \times 10^{4}\right.$ cells/well) were seeded and attached to 96 -well culture plates. The indicated doses $(0,0.5,1,2,10,50,100 \mu \mathrm{M})$ of ACF for different experiments were administered for 6-48 h. Cells were fixed in $10 \%$ trichloroacetic acid for $1 \mathrm{~h}$ at $4^{\circ} \mathrm{C}$ and washed five times with water. Fixed cells were stained with $0.4 \%$ sulforhodamine $\mathrm{B}$ for $15 \mathrm{~min}$ at room temperature and washed five times with $1 \%$ acetic acid. The incorporated dye was solubilized with $10 \mathrm{mM}$ Tris Base, $\mathrm{pH}$ 8.8. The absorbance was spectrophotometrically measured at $565 \mathrm{~nm}$ using an EL800 microplate reader (BioTek Instruments, Inc.).

Cell death assay. Cell death was assayed using the Muse Annexin V \& Dead Cell kit (cat. no. MCH100105; Luminex Corporation) according to the manufacturer's protocol. Briefly, $5 \times 10^{5}$ cells were collected, washed using cold phosphate-buffered saline (PBS), and resuspended in a medium containing $1 \%$ FBS. Following staining with the Muse Annexin V and Dead Cell reagent at room temperature for $20 \mathrm{~min}$, cells were analyzed using the Muse Cell Analyzer (Luminex Corporation). Cell death was detected as the percentage of Annexin V-and/or 7-amino-actinomycin D (7-AAD)-positive cells.

Caspase $-3 / 7$ activity assay. Caspase-3/7 activity was analyzed using the Muse Caspase-3/7 kit (cat. no. MCH100108; Luminex Corporation). Briefly, $5 \times 10^{5}$ cells were collected 
and washed using cold PBS. Cells were resuspended in $1 \mathrm{X}$ assay buffer BA and mixed with Muse Caspase-3/7 reagent. Following $30 \mathrm{~min}$ of incubation at $37^{\circ} \mathrm{C}$, Muse Caspase 7-AAD working solution was added to the cells. The cells were detected using the Muse Cell Analyzer and results were analyzed using Muse Cell Analyzer software version 1.6 (both from Luminex Corporation). The results were reported as the percentages of live cells (lower left panel, caspase-3/7-negative and 7-AAD-negative), apoptotic cells exhibiting caspase-3/7 activity (lower right panel, caspase-3/7 positive and 7-AAD-negative), late apoptotic/dead cells (upper right panel, caspase-3/7-positive and 7-AAD-positive), and necrotic cells (upper left panel, caspase-3/7-negative and 7-AAD-positive).

Western blot analysis. Cells were lysed using lysis buffer (cat. no. 9803S; Cell Signaling Technology, Inc.) supplemented with a protease inhibitor cocktail (cat. no. 11697498001; Roche Diagnostics $\mathrm{GmbH}$ ) for $30 \mathrm{~min}$ at $4^{\circ} \mathrm{C}$. Protein concentration was measured by bicinchoninic acid (BCA) assay. A total of $10-50 \mu \mathrm{g}$ of protein per lane were separated using $8-14 \%$ sodium dodecyl sulfate-polyacrylamide gel electrophoresis (SDS-PAGE) and transferred to nitrocellulose membranes (GE Healthcare Life Sciences; Cytiva). The membranes were blocked using 2\% skim milk (product no. 70166; Sigma-Aldrich; Merck KGaA) for $1 \mathrm{~h}$ at room temperature followed by immunoblotting with specific primary antibodies (BCL-XL, BCL-2, GAPDH, $\beta$-actin, MCL-1, p-MCL1, XIAP, XAF1, cleaved PARP, GSK-3 $\beta$, and p-GSK-3 $\beta$, ubiquitin, caspase- 8 and caspase-9) at a dilution of 1:2,000 overnight at $4^{\circ} \mathrm{C}$. Horseradish peroxidase-conjugated anti-mouse (product no. 7076P2) and anti-rabbit (product no. 7074P2; both from Cell Signaling Technology, Inc.) secondary antibodies were incubated at a dilution of 1:1,000 at room temperature for $1 \mathrm{~h}$. Following three washes with Tris-buffered saline $0.1 \%$ Tween-20, immunoreactive bands were visualized using an enhanced chemiluminescence detection system (Cyanagen $\mathrm{Srl}$ ).

Annexin $V$ and 7-AAD staining. Cells (4-5x $10^{5}$ cells/well) were seeded and attached to 6-well culture plates. The indicated doses $(0,1,2$ and $10 \mu \mathrm{M})$ of ACF were administered for $6-48 \mathrm{~h}$. Cells were resuspended in binding buffer or PBS and stained using Annexin V-APC and 7-AAD for $15 \mathrm{~min}$ at room temperature. Flow cytometry was performed using a FACSCanto II instrument (BD Biosciences) and FlowJo v10.8.0 software (Tree Star, Inc.).

RNA extraction, cDNA synthesis, and reverse transcriptionquantitative $(R T-q)$ PCR. The mRNA was isolated using TRIzol (Thermo Fisher Scientific, Inc.). Extracted RNA was subjected to complementary cDNA synthesis using TOPscript RT DryMIX (Enzynomics, Inc.) according to the manufacturer's protocol. qPCR was performed using SYBR Green TOPreal qPCR 2X PreMIX (Thermo Fisher Scientific, Inc.). Samples were normalized according to GAPDH (forward, 5'-GGAGCGAGATCCCTCCAAAAT-3' and reverse, 5'-GGC TGTTGTCATACTTCTCATGG-3') and compared with assigned expression of untreated cells using the MCL-1 primers (forward, 5'-CGACGGCGTAACAAACT-3' and reverse, 5'-GGAAGAACTCCACAAACCC-3'). Amplification was conducted with the CFX96 Touch Real-Time PCR detection system, a PCR machine (Bio-Rad Laboratories, Inc.). The thermocycling conditions consisted of initial denaturation at $95^{\circ} \mathrm{C}$ for $30 \mathrm{sec}$, followed by 40 cycles at $95^{\circ} \mathrm{C}$ for $5 \mathrm{sec}$, annealing at $60^{\circ} \mathrm{C}$ for $30 \mathrm{sec}$ and extension at $72^{\circ} \mathrm{C}$ for $30 \mathrm{sec}$. All reactions were examined in technical triplicate. The $2^{-\Delta \Delta \mathrm{Cq}}$ method (22) was used to calculate the relative gene expression.

Mitochondrial membrane potential and reactive oxygen species (ROS) measurement. Mitochondrial membrane potential and ROS generation were evaluated using specific fluorescence probe staining including tetramethylrhodamine-ethyl ester-perchlorate (TMRE; Thermo Fisher Scientific, Inc.), and 6-chloromethyl-2',7'-dichlorodihydrofluorescein diacetate acetyl ester (CM-H2DCFDA; Thermo Fisher Scientific, Inc.), respectively, as previously reported (23). Briefly, cells exposed to ACF $(2 \mu \mathrm{M})$ and ABT-263 $(1 \mu \mathrm{M})$ for 2,6 or $24 \mathrm{~h}$ were incubated in $200 \mathrm{nM}$ TMRE and $10 \mu \mathrm{M}$ CM-H2DCFDA probe for $30 \mathrm{~min}$ at $37^{\circ} \mathrm{C}$. Following washing twice using PBS, the fluorescence signals of TMRE and DCF-DA were detected and analyzed using a confocal microscope (LSM 700; Carl Zeiss AG).

Post-translational regulation and immunoprecipitation. For post-translational regulation of MCL-1, MDA-MB-231 and HS578T, cells were treated with cycloheximide (CHX; $10 \mu \mathrm{g} / \mathrm{ml})$ and/or ACF $(10 \mu \mathrm{M})$ and after 0,1 and $2 \mathrm{~h}$ the expression of MCL-1 was determined using western blot analysis. For the proteasomal regulation study, MDA-MB-231 and HS578T cells were treated with MG-132 (10 $\mu \mathrm{M})$ and/or ACF $(10 \mu \mathrm{M})$ and after $6 \mathrm{~h}$ the expression of MCL-1 was determined using western blot analysis. For ubiquitination study, HS578T cells were treated with MG-132 $(10 \mu \mathrm{M})$ and/or ACF $(10 \mu \mathrm{M})$ and after $6 \mathrm{~h}$ the cells were harvested and washed twice with PBS. Cells were then resuspended in Pierce ${ }^{\circledR}$ IP Lysis Buffer (25 mM Tris-HCl pH 7.4, $150 \mathrm{mM} \mathrm{NaCl}, 1 \% \mathrm{NP}-40,1 \mathrm{mM}$ EDTA, 5\% glycerol) mixed with protease inhibitor and EDTA. A total of $100 \mu \mathrm{g}$ of protein was incubated with anti-MCL-1 antibody for $2 \mathrm{~h}$ at $4^{\circ} \mathrm{C}$. Subsequently, $20 \mu \mathrm{l}$ of resuspended Protein A/G PLUS-Agarose (cat. no. sc-2003; Santa Cruz Biotechnology, Inc.) was added and incubated overnight at $4^{\circ} \mathrm{C}$. Immunoprecipitates were collected and washed 4 times with PBS by centrifugation at $1,000 \mathrm{x}$ g for $5 \mathrm{~min}$ at $4^{\circ} \mathrm{C}$. The supernatant was discarded and the beads were resuspended with $40 \mu 1$ of electrophoresis buffer and analyzed by SDS-PAGE and western blotting.

Combination index (CI) analyses. Using the CompuSyn software (CompuSyn v1.0; CompuSyn Inc.), the CI values were calculated according to the cell viability at corresponding concentrations. The $\mathrm{CI}$ value, $\mathrm{CI}<1$ indicates a synergistic effect, $\mathrm{CI}=1$ indicates an additive effect and $\mathrm{CI}>1$ indicates and antagonistic effect $(24,25)$.

Statistical analyses. Differences between groups were analyzed using one-way ANOVA and subsequent Tukey's multiple comparison post hoc test. Error bars represent \pm standard deviation from three independent experiments. All statistical analyses were conducted using Graph-Pad Prism 
A

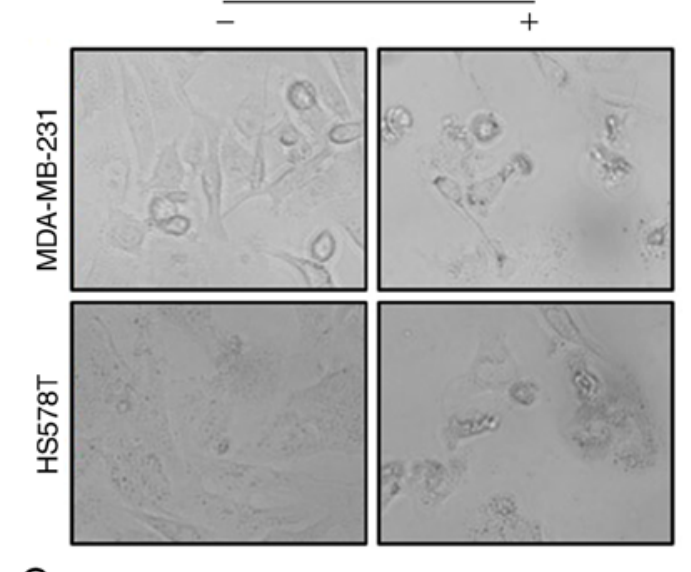

C

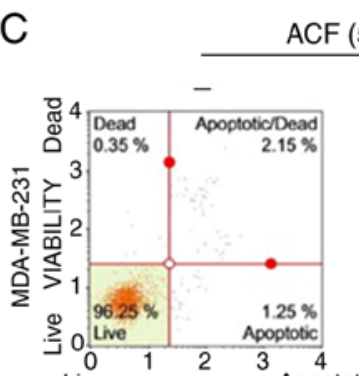

Live CASPASE-3/7 Apoptotic Live CASPASE-3/7 Apoptotic

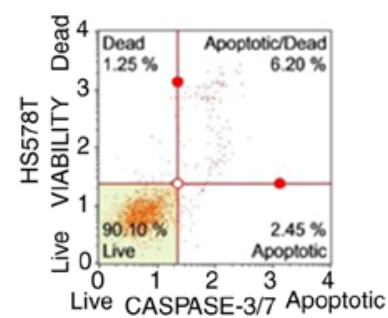

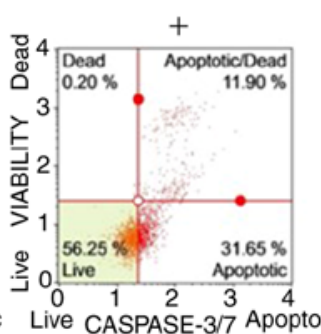

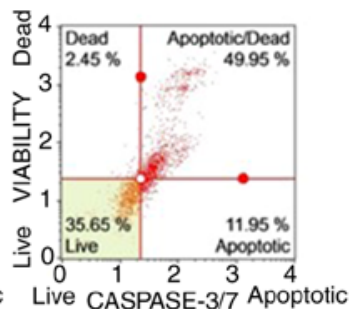

B

$\theta 6 \mathrm{~h} \quad \boxminus 24 \mathrm{~h}$

$\triangle 48 h$
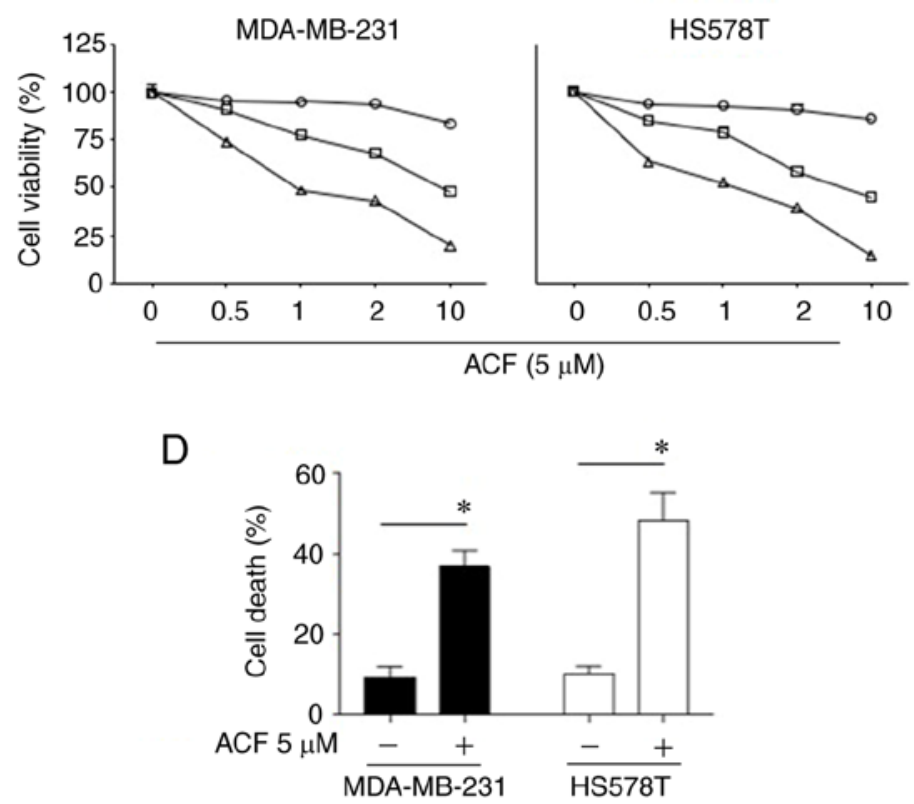

E

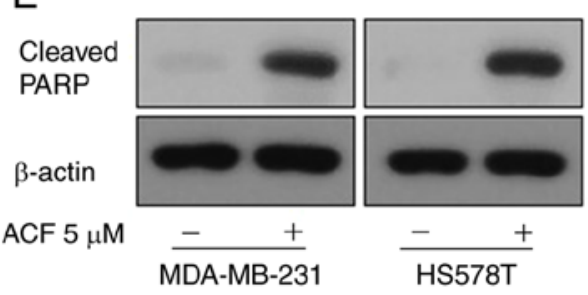

Figure 1. Apoptosis is promoted by (ACF) in triple-negative breast cancer cell lines in a time and dose-dependent manner. (A) Microscopic images (magnification, x100) of MDA-MB-231 and HS578T cells. (B) Effects of ACF on the viability of MDA-MB-231 and HS578T cells. The cells were treated with various concentrations $(0,0.5,1,2$ and $10 \mu \mathrm{M})$ of ACF for 6,24 and $48 \mathrm{~h}$, and cell viability was determined using the sulforhodamine B assay. (C) MDA-MB-231 and HS578T cells were treated with 0 or $5 \mu \mathrm{M}$ ACF for $24 \mathrm{~h}$. Caspase-3/7 activity was analyzed using Muse Caspase-3/7 kit, as described in the Materials and methods. A total of 4 populations of cells were distinguished: Live [caspase-3/7(-)/7-AAD(-)], apoptotic [caspase-3/7(+)/7-AAD(-)], apoptotic/dead cells [caspase-3/7(+)/7-AAD(+)], and necrotic [caspase-3/7(-)/7-AAD(+)]. (D) MDA-MB-231 and HS578T cells were treated with 0 or $5 \mu \mathrm{M}$ ACF for 24 h. Cell death was detected as the percentage of Annexin V and/or 7-AAD-positive cells. The results are expressed as the percentage of surviving cells over control cells. Each value is reported as the mean \pm standard deviation and is representative of results obtained from three independent experiments. ${ }^{*}<0.05$ compared with non-treated cells. (E) MDA-MB-231 and HS578T cells were treated with 0 or $5 \mu \mathrm{M}$ ACF for 24 h and then western blot analysis for cleaved PARP expression was performed. $\beta$-actin served as the loading control. ACF, acriflavine; 7-AAD, 7-amino-actinomycin D.

Version 4.0 (GraphPad Software, Inc.). P<0.05 was considered to indicate a statistically significant difference.

\section{Results}

ACF induces apoptosis in TNBC cells in time and dosedependent manners. To assess whether ACF has anticancer activity on TNBC cells under normoxic conditions, the effect of ACF on survival and apoptosis in MDA-MB-231 and HS578T cells was examined. ACF ( $5 \mu \mathrm{M}$ for $72 \mathrm{~h})$ induced typical apoptosis morphologies in TNBCs characterized by shrinkage of cells and fragmentation into ultra-structured apoptotic bodies (Fig. 1A). The cell viability assay revealed that the anticancer activity of ACF was dose- and time-dependent (Fig. 1B). Flow cytometric analysis revealed that ACF-induced cell death was apoptosis via activation of caspase-3/7 (Fig. 1C and D). In addition, ACF-treated cells exhibited increased levels of cleaved PARP, which is a known cellular substrate of caspases (Fig. 1E). Then, the anticancer effect of ACF on different GBM (U87, U251, and U343) and lung cancer (A549, NCI-H69) cell lines was explored. Cytotoxicity and FACS data (Fig. S1) also revealed the anticancer activity of ACF on GBM and lung cancer cell lines.

ACF causes apoptosis via the intrinsic pathway. To determine whether apoptosis signaling occurs via the mitochondriamediated intrinsic or death receptor-mediated extrinsic apoptotic signaling pathway, the accumulation of ROS and the level of mitochondrial membrane potential was assessed using TMRE. ROS levels and mitochondrial membrane potential were not altered following treatment with ABT-263, a BCL-2 protein inhibitor. However, ACF markedly increased the ROS levels within $2 \mathrm{~h}$ and reduced the mitochondrial membrane potentials at $6 \mathrm{~h}$ following treatment (Fig. 2). From a molecular 
A
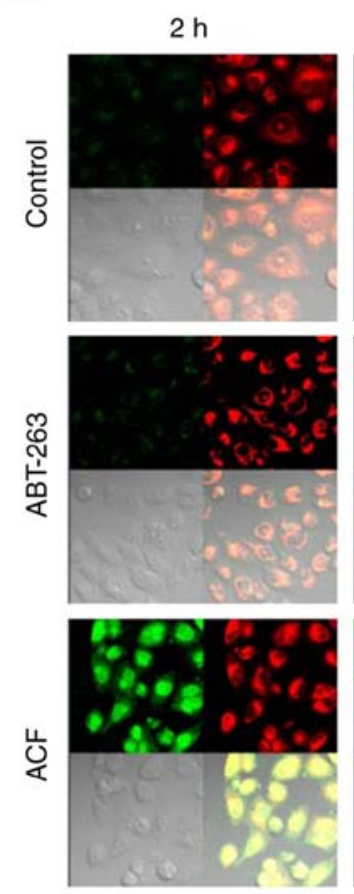

$6 \mathrm{~h}$
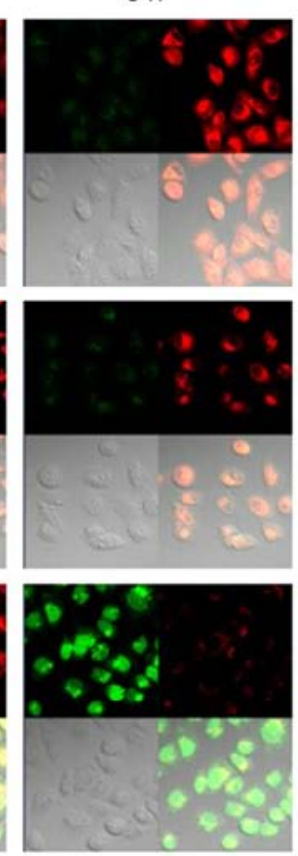
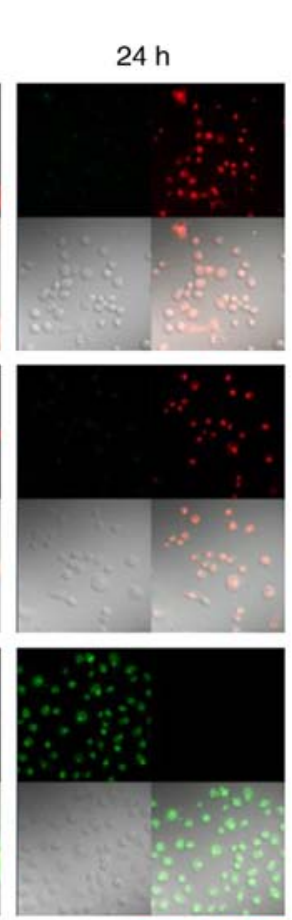

ROS/TMRE

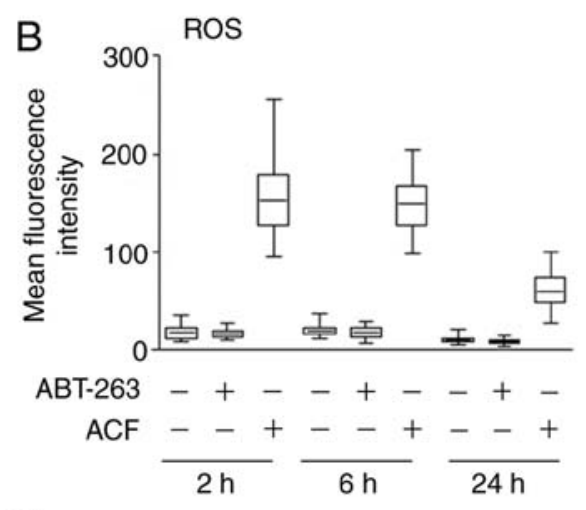

C

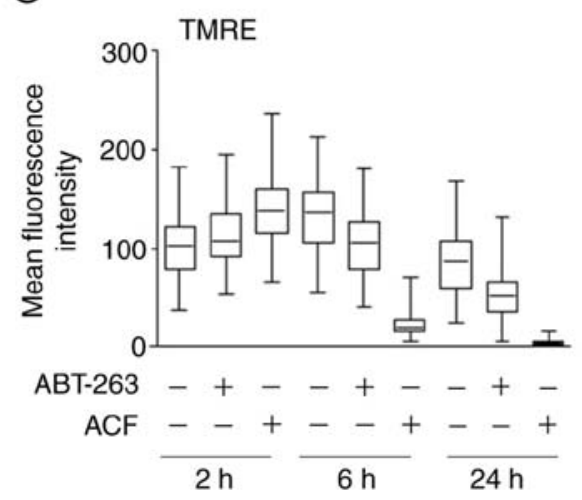

Figure 2. ACF induces mitochondrial damage and ROS. (A) HS578T cells were treated with ABT-263 $(1 \mu \mathrm{M})$ and ACF $(2 \mu \mathrm{M})$, and mitochondria membrane potential and ROS generation were evaluated using specific fluorescence probe staining including tetramethylrhodamine-ethyl ester-perchlorate, and 6-chloromethyl-2',7'-dichlorodihydrofluorescein diacetate, acetyl ester, respectively. Fluorescence images (magnification, x200) were captured after treating cells with each drug for 2, 6 and $24 \mathrm{~h}$. (B and C) Mean fluorescence intensity of control cells and cells treated with ABT-263 and ACF was evaluated. ACF, acriflavine; ROS, reactive oxygen species; TMRE, tetramethylrhodamine-ethyl ester-perchlorate.

point of view, the expression of caspase- 8 and caspase- 9 in ACF-treated $(5 \mu \mathrm{M})$ cells was analyzed via western blot analysis. A total of $24 \mathrm{~h}$ following ACF treatment, the expression of caspase- 9 was decreased while the expression of caspase- 8 remained unchanged and the cleaved form of caspase- 9 was not detected (Fig. S2). Collectively, these data suggested that ACF induces apoptosis via the intrinsic pathway.

Antitumor effect of ACF is mediated by the downregulation of MCL-1 protein. To evaluate the mechanism of ACF-induced intrinsic apoptosis, the protein levels of anti-apoptotic BCL-2 family proteins were determined using western blotting. ACF downregulated the protein levels of MCL-1, but not of other BCL-2 family proteins (Fig. 3A). The time kinetic study revealed that the MCL-1 protein level rapidly decreased and completely disappeared at 3-6 h following ACF treatment, while the majority of the cleaved PARP was formed $24 \mathrm{~h}$ following treatment (Fig. 3B). These results suggested the presence of other molecules between MCL-1 and cleaved PARP during ACF-mediated apoptosis. To determine which molecules linked MCL-1 downregulation and PARP cleavage, the XAF1 and XIAP protein levels were evaluated. Expression of XAF1 protein was increased and expression of XIAP was decreased at $24 \mathrm{~h}$ following the ACF treatment (Fig. 3C). Then, XAF1 and XIAP expression was evaluated at serial time-points. The results revealed the increased expression of XAF1 at 1, 3, 10 and $24 \mathrm{~h}$ following ACF treatment and decreased expression at $6 \mathrm{~h}$. Expression of XIAP was decreased at 1, 3, 10 and $24 \mathrm{~h}$ but increased at $6 \mathrm{~h}$ following ACF treatment in the MDA-MB-231 cell line. In the HS578T cells, XAF1 increased at 3,6, 10 and $24 \mathrm{~h}$ but decreased at $1 \mathrm{~h}$ and XIAP decreased at 1, 10 and $24 \mathrm{~h}$ and increased at 3 and $6 \mathrm{~h}$ following ACF treatment (Fig. 3D). In addition, MCL-1 downregulation was also observed both in hypoxic and normal conditions (Fig. S3). The aforementioned experiments entailed that ACF treatment induces an antitumor effect by downregulating MCL-1 not HIF-1 and it may also be associated with the expression of XAF1 and XIAP in TNBC cells.

ACF induces downregulation of MCL-1 at a transcriptionaland post-translational-dependent manner. MCL-1 protein expression is regulated in multiple steps: transcription and post-translation. First, the mRNA levels of MCL-1 were evaluated using RT-qPCR. ACF decreased the levels of MCL-1 mRNA in MDA-MB-231 and HS578T cells (Fig. 4A). Secondly, it was evaluated if MCL-1 degradation occurs under CHX $(10 \mu \mathrm{g} / \mathrm{ml})$, an inhibitor of protein biosynthesis. ACF $(10 \mu \mathrm{M})$ decreased MCL-1 expression even following inhibition of translation (Fig. 4B). This indicated that MCL-1 is also downregulated following translation. Next, it was evaluated whether ACF increases proteasomal degradation of MCL-1 using a proteasome inhibitor, MG-132 $(10 \mu \mathrm{M})$. The decrease in MCL-1 by ACF was blocked using MG-132 (Fig. 4C). Interestingly, cells treated with MG-132 alone demonstrated markedly higher MCL-1 protein levels than those treated with both MG-132 and ACF. Lastly, the ubiquitination of 


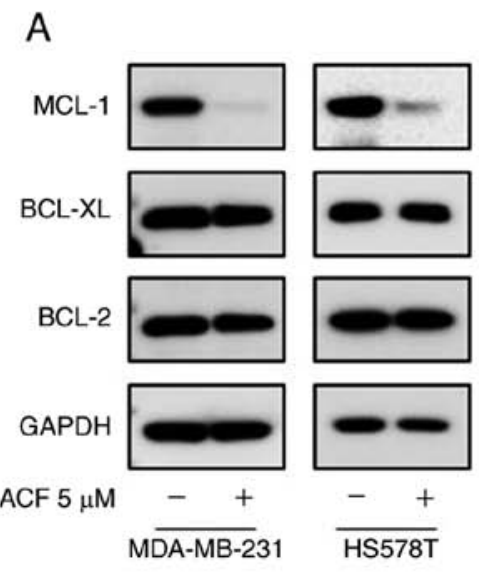

C

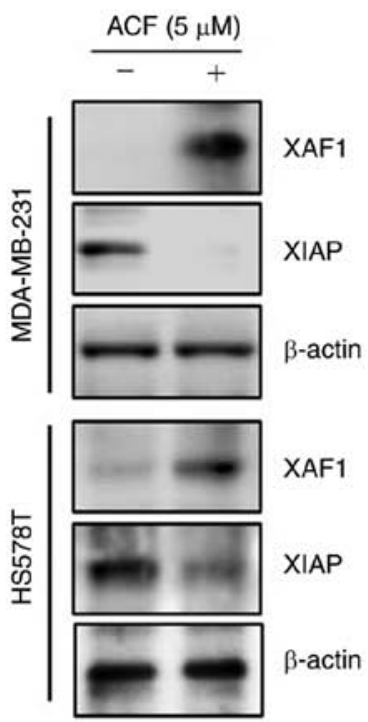

B

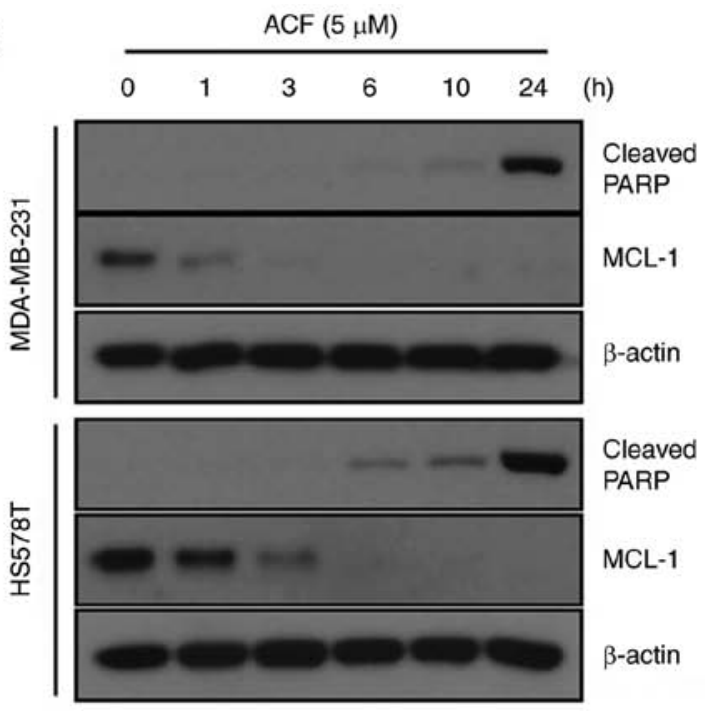

D
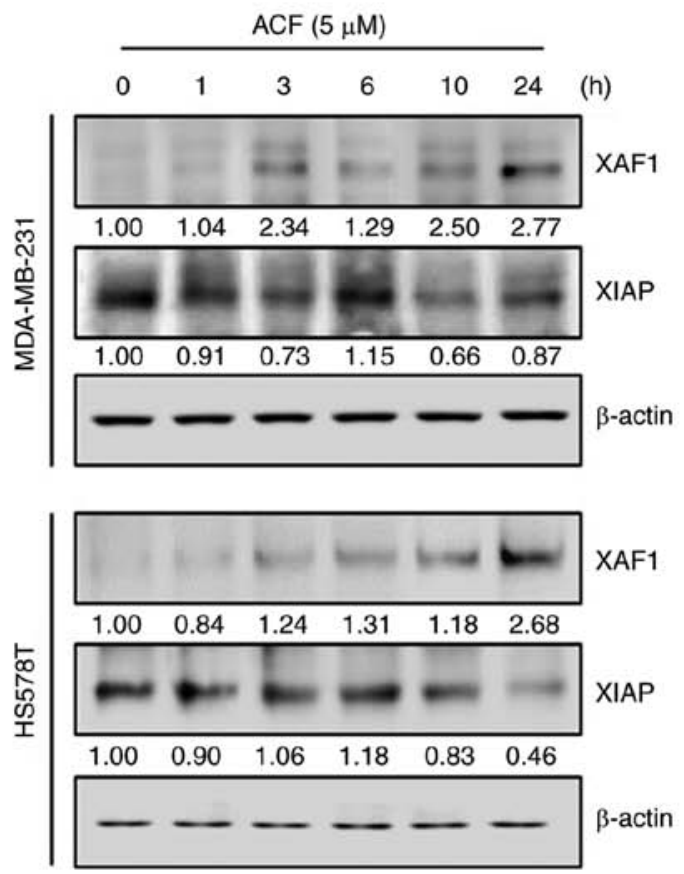

Figure 3. ACF suppresses anti-apoptotic proteins MCL-1 and XIAP. (A) MDA-MB-231 and HS578T cells were treated with 0 or $5 \mu \mathrm{M}$ ACF for $6 \mathrm{~h}$ and then western blot analysis for MCL-1, XIAP, BCL-2 and BCL-XL expression was performed. (B) MDA-MB-231 and HS578T cells were treated with $5 \mu$ M ACF and expression of cleaved PARP was assessed after $0,1,3,6,10$ and $24 \mathrm{~h}$ using western blot analysis. (C) MDA-MB-231 and HS578T cells were treated using 0 or $5 \mu \mathrm{M}$ ACF for $24 \mathrm{~h}$ and expression of XAF1 and XIAP was assessed using western blot analysis. (D) MDA-MB-231 and HS578T cells were treated using $5 \mu \mathrm{M}$ ACF for $0,1,3,6,10$ and $24 \mathrm{~h}$ and the expression of XAF1 and XIAP was assessed using western blot analysis. In all experiments, GAPDH or $\beta$-actin served as the loading control. ACF, acriflavine; MCL-1, myeloid cell leukemia sequence 1; BCL-2, B-cell lymphoma 2.

MCL-1 protein was evaluated. Western blot data followed by immunoprecipitation also revealed increased ubiquitination of MCL-1 protein by ACF treatment (Fig. 4D). A higher ubiquitination level in cells treated with MG-132 was also consistent with the previous experiment (Fig. 4C). However, the level of GSK3 $\beta$ remained unchanged when treated with ACF (Fig. S4). Collectively, these data indicated that MCL-1 downregulation by ACF occurs at transcriptional and post-translational levels.

$A C F$ and $A B T-263$ work synergistically by overcoming the resistance to $A B T-263$. To determine whether ACF may be used as a treatment strategy, HS578T cells were treated with ABT-263, a BCL-2 protein inhibitor, with or without ACF.
While ABT-263 or ACF alone was not so effective in inducing apoptosis, when combined with $2 \mu \mathrm{M} \mathrm{ACF}$, apoptosis was induced in more than $30 \%$ of cells. Importantly, apoptosis induced by the combination of ABT-263 and ACF was five times greater than that by ABT-263 or ACF alone (Fig. 5A). As previously reported (26), ABT-263 induced MCL-1 expression in TNBC cells, and ACF treatment prevented MCL-1 induction (Fig. 5B). The combination treatment of ACF and ABT-263 revealed synergy in both MDA-MB-231 and HS578T cells (Figs. 5C and D and S3). To determine the molecular pathways involved, the expression of caspase- 8 and caspase- 9 was analyzed. Although the expression of active caspase- 9 was detected after $24 \mathrm{~h}$, caspase- 8 remained unaltered when treated with ACF (Fig. S2). However, the expression of both caspases 

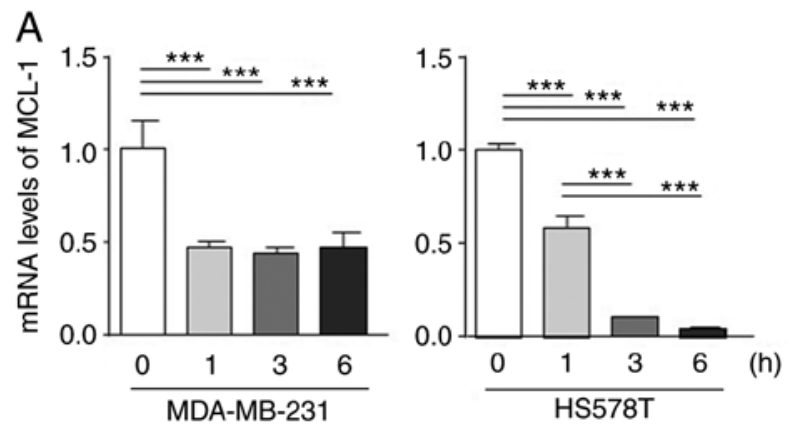

B
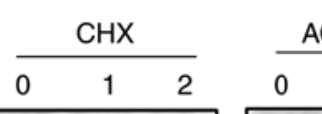

$\mathrm{ACF}+\mathrm{CHX}$
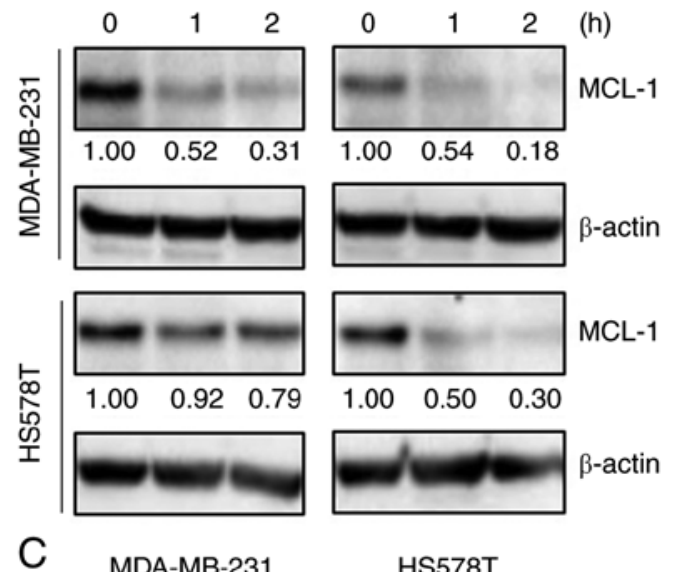

C

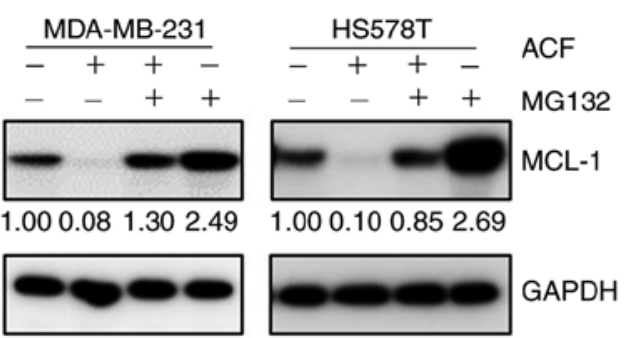

D

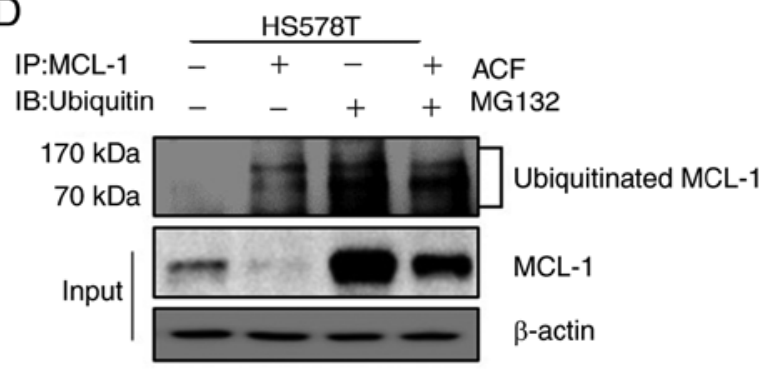

Figure 4. MCL-1 downregulation occurs at transcriptional and post-translational levels. (A) MDA-MB-231 and HS578T cells were treated using $5 \mu \mathrm{M}$ ACF and the expression of MCL-1 mRNA was evaluated after 0, 1, 3, and $6 \mathrm{~h}$ using reverse transcription-quantitative PCR. Each value is reported as the mean \pm standard deviation and is representative of results obtained from three independent experiments. (B) MDA-MB-231 and HS578T cells were incubated with cycloheximide $(10 \mu \mathrm{g} / \mathrm{ml})$, and/or ACF $(10 \mu \mathrm{M})$ and after 0,1 and $2 \mathrm{~h}$ the expression of MCL-1 was determined using western blot analysis. (C) MDA-MB-231 and HS578T cells were incubated with ACF and proteasome inhibitor, MG-132, and expression of MCL-1 was determined using western blot analysis. (D) HS578T cells were treated with $10 \mu \mathrm{M}$ ACF and and/or MG-132, and after $6 \mathrm{~h} \mathrm{MCL-1} \mathrm{was} \mathrm{pulled} \mathrm{down} \mathrm{and}$ the ubiquitination level was analyzed using western blotting. ${ }^{* * *} \mathrm{P}<0.001$ compared with non-treated cells. ACF, acriflavine; MCL-1, myeloid cell leukemia sequence 1 .

was not detected $6 \mathrm{~h}$ following ACF treatment. Interestingly, combination of ACF and ABT-263 activated both caspases suggesting the involvement of both an intrinsic and extrinsic apoptotic pathway in the combination treatment (Fig. 5E). To determine whether the synergistic effect of ACF and ABT-263 may be observed in other cancer types, GBM (U87, U343,U251) and NSCLC (A549) cells were treated with ACF and ABT-263. Immunoblotting data revealed that the ABT-263 treatment upregulated the expression of MCL-1. However, when treated with $2 \mu \mathrm{M}$ ACF, the expression of MCL-1 was downregulated again (Fig. 6A). Addition of ACF to ABT-263 also increased apoptosis in GBM (U87, U251 and U343) and NSCLC (A549) cell lines (Fig. 6B and C) compared with ABT-263 single therapy. Analysis of CI revealed synergistic apoptosis in U251, U343 and A549 cell lines (Fig. S5). Cell viability data also suggested that the combination treatment could eliminate cancer cells in a dose-dependent manner (Fig. 6D). These data suggested that ACF could act synergistically with ABT-263 by preventing MCL-1 upregulation.

\section{Discussion}

The BCL-2 family proteins modulate the intrinsic (mitochondrial) apoptotic pathway via the balance of pro- and anti-apoptotic proteins. The BCL-2 family consists of three main subclasses depending on the location of BCL-2 homology $(\mathrm{BH})$ and function: multidomain anti-apoptotic (BCL-2, MCL-1 and BCL-XL), multidomain pro-apoptotic (BAX and BAK), and BH3-only pro-apoptotic (BIM, PUMA and NOXA) (2). Anti-apoptotic BCL-2 family members regulate apoptosis by isolating the stimulants from interacting with BAX and BAK $(27,28)$. BH3 proteins (BAD and NOXA) are considered to cause apoptosis by engaging with anti-apoptotic proteins, freeing activators to stimulate BAX and BAK (29). Furthermore, anti-apoptotic BCL-2 family proteins seldom directly inhibit BAX and BAK, both inducing cell survival directly and indirectly, by sequestering BH3-only proteins $(27,28)$. One of the most well-known and clinically advanced BCL-2 family target therapies is ABT-737 and its clinical analog ABT-263 (navitoclax). Their molecular structure mimics BAD BH3 and binds to the $\mathrm{BH} 3$ binding groove of BCL-2, BCL-XL, and BCL-W $(30,31)$. However, the potency of BCL-2/BCL-XL inhibitors has been underwhelming (32). Their major limitation is the unexpected upregulation of MCL-1. In addition, the most frequently amplified gene in inhibitions of BCL-XL and BCL-2 is MCL-1, gaining significant interest in anticancer therapeutics.

MCL-1 is overexpressed in a wide range of cancers, including both solid and hematologic malignancies such as liver, ovarian, prostate, hematologic, and breast cancers (33-38). Previous studies revealed that MCL-1 is a crucial anti-apoptotic factor in TNBC $(39,40)$. For instance, MCL-1-knockdown TNBC cell lines revealed markedly reduced viability, while BCL-XL silencing had a modest effect (41). Furthermore, Balko et al revealed an overexpression of the MCL-1 gene in 54\% of TNBC patients who underwent neoadjuvant chemotherapy (42). They suggested that MCL-1 protects TNBC cells against apoptosis induced by cytotoxic chemotherapy (37). Moreover, the overexpression of MCL-1 has been proposed as a marker of poor prognosis in TNBC $(39,43)$. Overall, MCL-1 may be one of the prospective therapeutic targets for TNBC. Upregulation of anti-apoptotic 

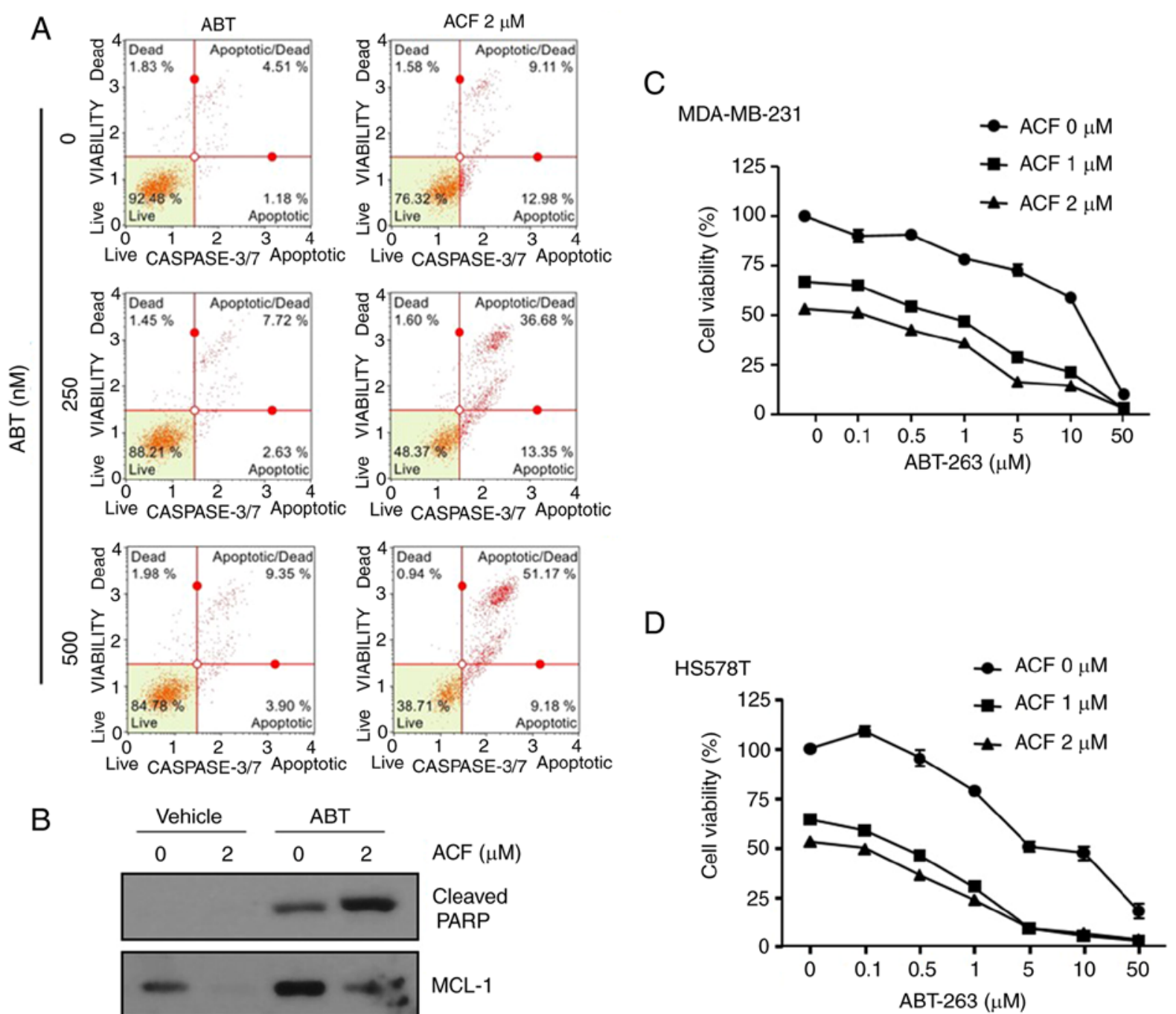

B

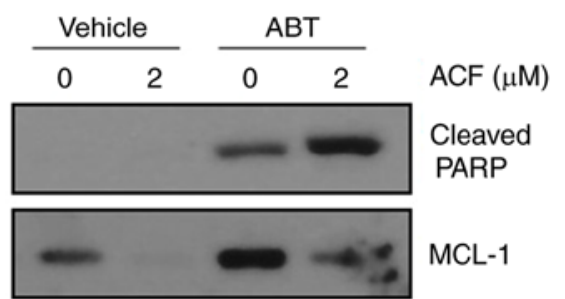

GAPDH

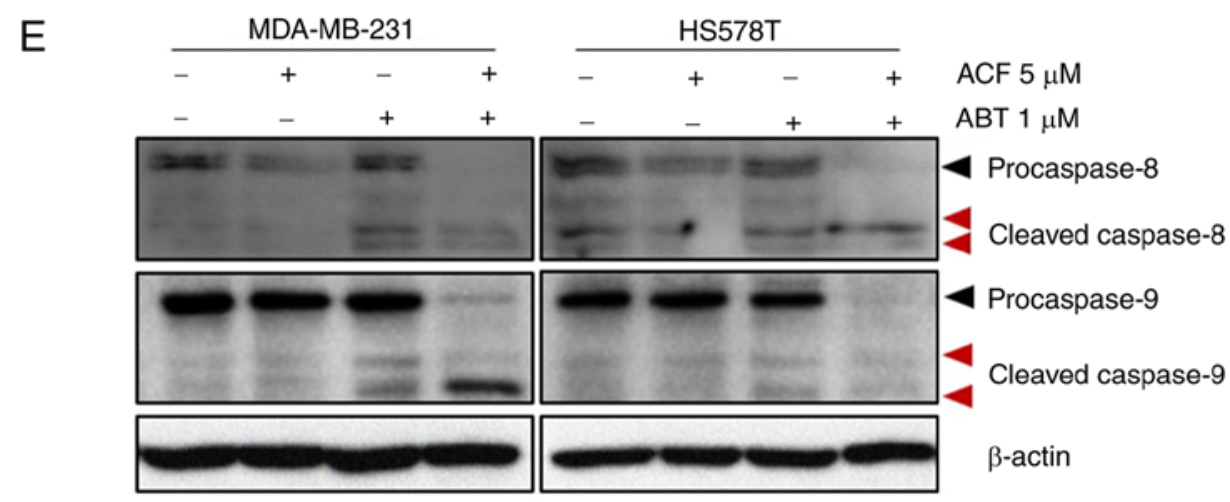

Figure 5. Antitumor effect of ACF and ABT-263 combination against TNBC cells. (A) HS578T cells were treated with indicated concentrations of ACF and/or ABT-263 for $24 \mathrm{~h}$. Caspase-3/7 activity was analyzed using Muse Caspase-3/7 kit, as described in the Materials and methods. A total of 4 populations of cells were distinguished: Live [caspase-3/7(-)/7-AAD(-)], apoptotic [caspase-3/7(+)/7-AAD(-)], apoptotic/dead cells [caspase-3/7(+)/7-AAD(+)], and necrotic [caspase-3/7(-)/7-AAD(+)]. (B) Cells were treated with ABT-263 (500 nM) and ACF $(2 \mu \mathrm{M})$ for $24 \mathrm{~h}$ and the expression of MCL-1 was evaluated using western blot analysis. (C and D) MDA-MB-231 and HS578T cells were treated with indicated concentrations of ACF and ABT-263 and cell viability was determined using the sulforhodamine B assay. (E) MDA-MB-231 and HS578T cells were treated with ACF (5 $\mu \mathrm{M})$ and/or ABT-263 (1 $\mu \mathrm{M})$ for $6 \mathrm{~h}$ and the expression of caspase- 8 and caspase- 9 and their cleaved forms was detected using western blot analysis. ACF, acriflavine; 7-AAD, 7-amino-actinomycin D.

BCL-2 family proteins hallmarks numerous cancers and occurs via various pathways. A prototype of this mechanism is MCL-1 upregulation, which contributes to protein stabilization by genetic inactivation of the ubiquitin ligase complex protein F-box and WD repeat domain-containing 7 (FBW7) $(9,44,45)$. Given the importance of inducing apoptosis 
A

GBM U87

GBM U343

GBM U251

NSCLC A549

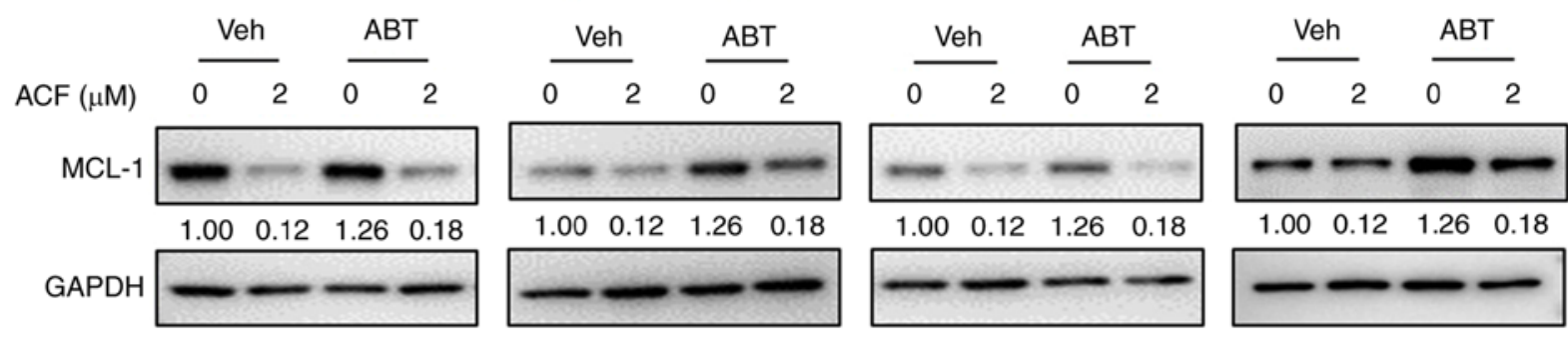

B

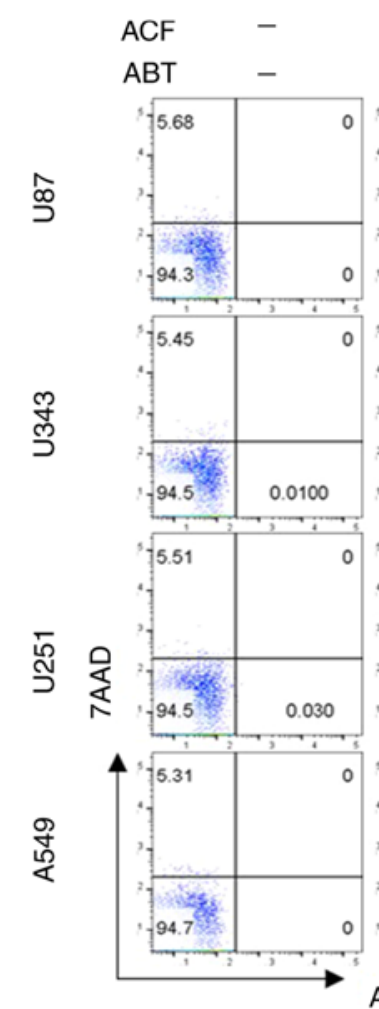

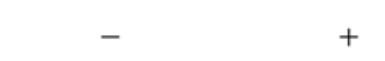
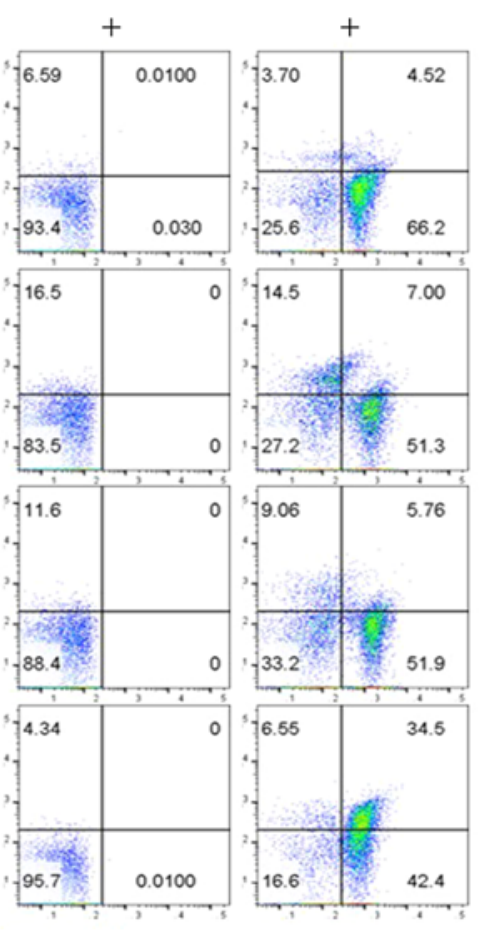

D

Annexin V
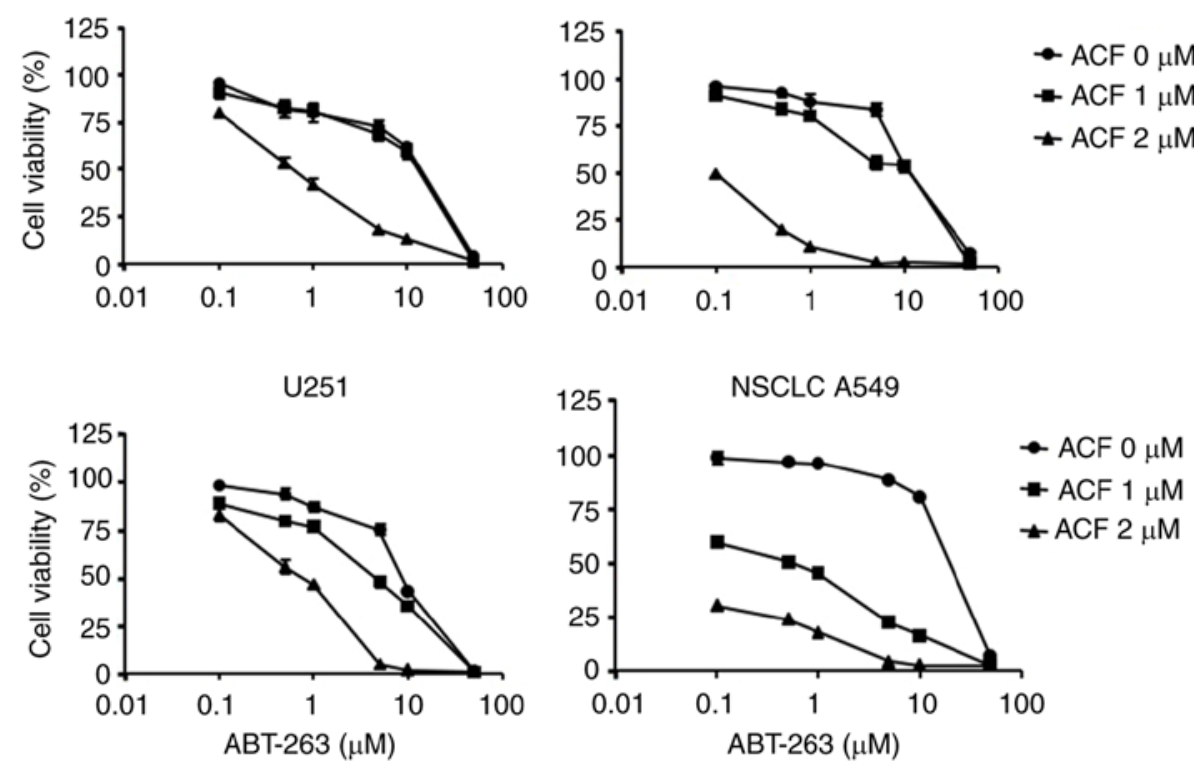

Figure 6. ACF overcomes the therapeutic resistance of ABT-263. (A) U87, U343, U251 and A549 cells were treated using ABT-263 and were incubated with 0 or $2 \mu \mathrm{M}$ ACF for $24 \mathrm{~h}$, and the expression of MCL-1 was detected using western blotting. (B) U87, U343, U251 and A549 cells were treated with ACF $(2 \mu \mathrm{M})$ and/or ABT-263 $(0.5 \mu \mathrm{M})$ for $24 \mathrm{~h}$ and apoptosis was evaluated using Annexin V and 7-AAD staining followed by FACS. (C) Quantitative analysis of the percentage of cell death (Annexin $\mathrm{V}^{+} / 7-\mathrm{AAD}^{-}$). Data are presented as the means \pm standard deviation from two independent experiments. (D) U87, U343, U251 and A549 cells were treated with indicated concentrations of ACF and ABT-263 and cell viability was determined using the sulforhodamine B assay. ${ }^{* *} \mathrm{P}<0.01$ compared with non-treated and ABT alone treated cells. ACF, acriflavine; 7-AAD, 7-amino-actinomycin D; MCL-1, myeloid cell leukemia sequence 1. 
in managing cancer treatment, agents inhibiting anti-apoptotic proteins have garnered interest as a therapeutic option against cancer. To overcome this MCL-1 upregulation by BCL-2 family inhibitors, trials were conducted to identify MCL-1 inhibitors in various cancers, including breast, hematologic, and lung cancers. They combined the pre-existing BCL-2 family inhibitors with novel MCL-1 inhibitors to overcome the potential resistance to BCL-2 family inhibitors and improve therapeutic outcomes $(46,47)$.

In the present study, it was revealed that ACF could regulate MCL-1 at the transcriptional and post-translational levels in breast cancer cells. The anticancer mechanism of ACF with MCL-1 downregulation was also revealed to be effective in lung and GBM cells. The limitation of the present study on the exact mechanism of MCL-1 decrease in lung cancer and GBM cells should be explored in further studies. Our study revealed that ACF promoted cell death of TNBC cells (MDA-MB-231 and HS578T) through the intrinsic apoptotic pathway in normoxia regardless of the HIF-1 pathway. Both ubiquitin-dependent and independent degradation of MCL-1 was reported. E3 ubiquitin-ligases confer a high degree of specificity to ubiquitination by recognizing target proteins. Ubiquitination of MCL-1 is mediated by five E3 ubiquitin ligases, including MCL-1 ubiquitin ligase E3 (MULE), glycogen synthase kinase $3 \beta$ (GSK3 $\beta$ ), $\beta$-transducin repeats-containing protein $(\beta-\operatorname{TrCP}), \mathrm{FBW} 7$, and tripartite motif-containing 17 (TRIM17) (48). However, different E3 ubiquitin-ligases appear to regulate MCL-1 protein expression in different cell types exposed to different stimuli. In the present study, the exact mechanism in the post-translational regulation of MCL-1 by $\mathrm{ACF}$ was not defined; however, ubiquitination was detected and GSK3 $\beta$ was not involved. Furthermore, the combination of ACF and ABT-263 generated apoptosis synergistically. This synergistic effect may be due to their independent inhibitory mechanism. ABT-263 stimulates TNBC apoptosis by inhibiting BCL-2, BCL-XL, and BCL-W. By contrast, our study revealed that ACF hinders MCL-1 and promotes TNBC apoptosis. It was assumed that as ABT and ACF work by regulating different BCL-2 family molecules, they compensated each other to enhance the antitumor effect. ACF is a mixture of two acridine analogs that are mostly utilized as antimicrobial agents (15). Goldie et al first reported the anticancer effect of ACF (49). Its potential as an anticancer agent has also been identified with the activity inhibiting the topo-isomerase and hypoxia-inducing factor (HIF) pathway by preventing the dimerization of HIF-1 $\alpha$ and HIF-1 $\beta(16,50)$. Previously, it has also been reported that ACF inhibited the epithelial-mesenchymal transition in pancreatic cancer cells induced by TGF- $\beta$ or cobalt chloride-induced hypoxia via reduction of the activating transcription factor 4 (20). $\mathrm{ACF}$ has also been revealed to be active in the prostate, pancreas, and colorectal tumor xenograft models in rodents when administered locally or systemically $(16,49,51)$. ACF revealed anticancer effects in hepatocellular carcinoma and lung adenocarcinoma under normoxic conditions $(18,19)$. The present study demonstrated cancer cell death by apoptosis caused by ACF in the normoxic state. Changes were primarily observed in mitochondrial membrane potentiality, which indicates an alteration in the function of the intrinsic apoptotic pathway. This indicates the importance of membranous stability, and only MCL-1 downregulation was observed without changes in various factors controlling membrane stability, including BCL-2. Considering these results, it is theorized that cancer cell death by ACF is due to MCL-1 inhibition, and not HIF-1 inhibition.

In the present study, the potential of ACF in treating TNBC cell lines in vitro, was investigated. To the best of our knowledge, this is the first study to suggest a novel MCL-1 inhibitory function of ACF. In addition, the present study revealed a synergistic antitumor effect with ABT-263. Furthermore, ACF demonstrated its therapeutic potency not only in TNBC but also in lung cancer and GBM cells.

\section{Acknowledgements}

Not applicable.

\section{Funding}

The present study was supported by the Korea Institute of Radiological and Medical Sciences (grant no. 50531-2021), which is funded by the Ministry of Science and Information and Communications Technology of the Korean government (IWK) and the Bio \& Medical Technology Development Program of the National Research Foundation (NRF) of Korea Funded by the Korean government (MSIT) under grant no. 2019M3A9H1103607.

\section{Availability of data and materials}

All data generated or analyzed during this study are included in this published article.

\section{Authors' contributions}

AL, HOJ, KSK, and SGP conceptualized the study and reviewed the writing of the manuscript. HYK and MMH wrote the original draft of the manuscript and analyzed the data. HOJ, HJ, JHP, IK, JYS, HKY, MMH and ICP investigated the anticancer effect of ACF on cancer cells and analyzed and curated the data. MMH, HJ, ICP, KSK, and SGP investigated the apoptotic signaling pathway and MCL-1 regulation mechanisms and analyzed the data. HKK and JH performed and analyzed the mitochondrial function assay. KSK and SGP were involved in supervision, funding acquisition, investigation, and project administration. KSK and SGP confirm the authenticity of all the raw data. All authors read and approved the final version of the manuscript.

\section{Ethics approval and consent to participate}

Not applicable.

\section{Patient consent for publication}

Not applicable.

\section{Competing interests}

The authors declare that they have no competing interests. 


\section{References}

1. Foulkes WD, Smith IE and Reis-Filho JS: Triple-negative breast cancer. N Engl J Med 363: 1938-1948, 2010.

2. Adams JM and Cory S: The Bcl-2 apoptotic switch in cancer development and therapy. Oncogene 26: 1324-1337, 2007.

3. Hanahan D and Weinberg RA: Hallmarks of cancer: The next generation. Cell 144: 646-674, 2011.

4. Adams JM and Cory S: The BCL-2 arbiters of apoptosis and their growing role as cancer targets. Cell Death Differ 25: 27-36,2018.

5. Mohammad RM, Muqbil I, Lowe L, Yedjou C, Hsu HY, Lin LT, Siegelin MD, Fimognari C, Kumar NB, Dou QP, et al: Broad targeting of resistance to apoptosis in cancer. Semin Cancer Biol 35 (Suppl): S78-S103, 2015.

6. Kang $\mathrm{MH}$ and Reynolds $\mathrm{CP}$ : Bcl-2 inhibitors: Targeting mitochondrial apoptotic pathways in cancer therapy. Clin Cancer Res 15: 1126-1132, 2009.

7. Ertel F, Nguyen M, Roulston A and Shore GC: Programming cancer cells for high expression levels of Mcll. EMBO Rep 14: 328-336, 2013

8. Craig RW: MCL1 provides a window on the role of the BCL2 family in cell proliferation, differentiation and tumorigenesis Leukemia 16: 444-454, 2002.

9. Beroukhim R, Mermel CH, Porter D, Wei G, Raychaudhuri S, Donovan J, Barretina J, Boehm JS, Dobson J, Urashima M, et al: The landscape of somatic copy-number alteration across human cancers. Nature 463: 899-905, 2010.

10. Ding Q, He X, Hsu JM, Xia W, Chen CT, Li LY, Lee DF, Liu JC, Zhong Q, Wang X and Hung MC: Degradation of Mcl-1 by beta-TrCP mediates glycogen synthase kinase 3-induced tumor suppression and chemosensitization. Mol Cell Biol 27: 4006-4017, 2007.

11. Young AI, Timpson P, Gallego-Ortega D, Ormandy CJ and Oakes SR: Myeloid cell leukemia 1 (MCL-1), an unexpected modulator of protein kinase signaling during invasion. Cell Adh Migr 12: 513-523, 2018.

12. Woo SM, Min KJ, Seo BR, Seo YH, Jeong YJ and Kwon TK: YM155 enhances ABT-737-mediated apoptosis through Mcl-1 downregulation in Mcl-1-overexpressed cancer cells. Mol Cell Biochem 429: 91-102, 2017.

13. Caenepeel S, Brown SP, Belmontes B, Moody G, Keegan KS Chui D, Whittington DA, Huang X, Poppe L, Cheng AC, et al: AMG 176, a selective MCL1 inhibitor, is effective in hematologic cancer models alone and in combination with established therapies. Cancer Discov 8: 1582-1597, 2018.

14. Ramsey HE, Fischer MA, Lee T, Gorska AE, Arrate MP, Fuller L, Boyd KL, Strickland SA, Sensintaffar J, Hogdal LJ, et al: A novel MCL1 inhibitor combined with venetoclax rescues venetoclaxresistant acute myelogenous leukemia. Cancer Discov 8 1566-1581, 2018

15. Wainwright M: Acridine-a neglected antibacterial chromophore J Antimicrob Chemother 47: 1-13,2001.

16. Lee K, Zhang H, Qian DZ, Rey S, Liu JO and Semenza GL: Acriflavine inhibits HIF-1 dimerization, tumor growth, and vascularization. Proc Natl Acad Sci USA 106: 17910-17915, 2009.

17. Zhang L, Huang G, Li X, Zhang Y, Jiang Y, Shen J, Liu J, Wang Q, Zhu J, Feng X, et al: Hypoxia induces epithelial-mesenchymal transition via activation of SNAI1 by hypoxia-inducible factor $-1 \alpha$ in hepatocellular carcinoma. BMC Cancer 13: 108, 2013

18. Lee CJ, Yue CH, Lin YJ, Lin YY, Kao SH, Liu JY and Chen YH: Antitumor activity of acriflavine in lung adenocarcinoma cell line A549. Anticancer Res 34: 6467-6472, 2014.

19. Lee CJ, Yue CH, Lin YY, Wu JC and Liu JY: Antitumor activity of acriflavine in human hepatocellular carcinoma cells. Anticancer Res 34: 3549-3556, 2014.

20. Dekervel J, Bulle A, Windmolders P, Lambrechts D, Van Cutsem E, Verslype C and van Pelt J: Acriflavine inhibits acquired drug resistance by blocking the epithelial-to-mesenchymal transition and the unfolded protein response. Transl Oncol 10: 59-69, 2017

21. Mangraviti A, Raghavan T, Volpin F, Skuli N, Gullotti D, Zhou J, Asnaghi L, Sankey E, Liu A, Wang Y, et al: HIF-1 $\alpha$ - targeting acriflavine provides long term survival and radiological tumor response in brain cancer therapy. Sci Rep 7: 14978, 2017.

22. Livak KJ and Schmittgen TD: Analysis of relative gene expression data using real-time quantitative PCR and the 2-(Delta Delta C(T) method. Methods 25: 402-408, 2001.
23. Jeong SH, Kim HK, Song IS, Lee SJ, Ko KS, Rhee BD, Kim N, Mishchenko NP, Fedoryev SA, Stonik VA and Han J: Echinochrome A protects mitochondrial function in cardiomyocytes against cardiotoxic drugs. Mar Drugs 12: 2922-2936, 2014

24. Chou TC: Theoretical basis, experimental design, and computerized simulation of synergism and antagonism in drug combination studies. Pharmacol Rev 58: 621-681, 2006.

25. Ashton JC: Drug combination studies and their synergy quantification using the Chou-Talalay method-letter. Cancer Res 75: 2400, 2015.

26. Williams MM, Lee L, Hicks DJ, Joly MM, Elion D, Rahman B, McKernan C, Sanchez V, Balko JM, Stricker T, et al: Key survival factor, Mcl-1, correlates with sensitivity to combined Bcl-2/Bcl-xL blockade. Mol Cancer Res 15: 259-268, 2017.

27. Certo M, Del Gaizo Moore V, Nishino M, Wei G, Korsmeyer S, Armstrong SA and Letai A: Mitochondria primed by death signals determine cellular addiction to antiapoptotic BCL-2 family members. Cancer Cell 9: 351-365, 2006

28. Lovell JF, Billen LP, Bindner S, Shamas-Din A, Fradin C, Leber B and Andrews DW: Membrane binding by tBid initiates an ordered series of events culminating in membrane permeabilization by Bax. Cell 135: 1074-1084, 2008

29. Kuwana T, Bouchier-Hayes L, Chipuk JE, Bonzon C, Sullivan BA, Green DR and Newmeyer DD: BH3 domains of BH3-only proteins differentially regulate Bax-mediated mitochondrial membrane permeabilization both directly and indirectly. Mol Cell 17: 525-535, 2005.

30. Willis SN, Chen L, Dewson G, Wei A, Naik E, Fletcher JI, Adams JM and Huang DC: Proapoptotic bak is sequestered by Mcl-1 and Bcl-xL, but not Bcl-2, until displaced by BH3-only proteins. Genes Dev 19: 1294-1305, 2005.

31. Edlich F, Banerjee S, Suzuki M, Cleland MM, Arnoult D, Wang C, Neutzner A, Tjandra N and Youle RJ: Bcl-x(L) retrotranslocates bax from the mitochondria into the cytosol. Cell 145: 104-116, 2011.

32. Oltersdorf T, Elmore SW, Shoemaker AR, Armstrong RC, Augeri DJ, Belli BA, Bruncko M, Deckwerth TL, Dinges J, Hajduk PJ, et al: An inhibitor of Bcl-2 family proteins induces regression of solid tumours. Nature 435: 677-681, 2005.

33. Souers AJ, Leverson JD, Boghaert ER, Ackler SL, Catron ND, Chen J, Dayton BD, Ding H, Enschede SH, Fairbrother WJ, et al: ABT-199, a potent and selective BCL-2 inhibitor, achieves antitumor activity while sparing platelets. Nat Med 19: 202-208, 2013.

34. Bartlett NL: Highlights in lymphoma from the 2013 American society of hematology annual meeting and exposition: Commentary. Clin Adv Hematol Oncol 12 (Suppl 6): 18-23, 2014.

35. Sieghart W, Losert D, Strommer S, Cejka D, Schmid K, Rasoul-Rockenschaub S, Bodingbauer M, Crevenna R, Monia BP, Peck-Radosavljevic M and Wacheck V: Mcl-1 overexpression in hepatocellular carcinoma: A potential target for antisense therapy. J Hepatol 44: 151-157, 2006.

36. LaBelle JL, Katz SG, Bird GH, Gavathiotis E, Stewart ML, Lawrence C, Fisher JK, Godes M, Pitter K, Kung AL and Walensky LD: A stapled BIM peptide overcomes apoptotic resistance in hematologic cancers. J Clin Invest 122: 2018-2031, 2012

37. Reiner T, de Las Pozas A, Parrondo R, Palenzuela D, Cayuso W, Rai P and Perez-Stable C: Mcl-1 protects prostate cancer cells from cell death mediated by chemotherapy-induced DNA damage. Oncoscience 2: 703-715, 2015.

38. Young AI, Law AM, Castillo L, Chong S, Cullen HD, Koehler M, Herzog S, Brummer T, Lee EF, Fairlie WD, et al: MCL-1 inhibition provides a new way to suppress breast cancer metastasis and increase sensitivity to dasatinib. Breast Cancer Res 18: 125, 2016.

39. Zervantonakis IK, Iavarone C, Chen HY, Selfors LM, Palakurthi S, Liu JF, Drapkin R, Matulonis U, Leverson JD, Sampath D, et al: Systems analysis of apoptotic priming in ovarian cancer identifies vulnerabilities and predictors of drug response. Nat Commun 8: 365, 2017.

40. Campbell KJ, Dhayade S, Ferrari N, Sims AH, Johnson E, Mason SM, Dickson A, Ryan KM, Kalna G, Edwards J, et al: MCL-1 is a prognostic indicator and drug target in breast cancer. Cell Death Dis 9: 19, 2018.

41. Goodwin CM, Rossanese OW, Olejniczak ET and Fesik SW: Myeloid cell leukemia-1 is an important apoptotic survival factor in triple-negative breast cancer. Cell Death Differ 22: 2098-2106, 2015.

42. Balko JM, Giltnane JM, Wang K, Schwarz LJ, Young CD Cook RS, Owens P, Sanders ME, Kuba MG, Sánchez V, et al: Molecular profiling of the residual disease of triple-negative breast cancers after neoadjuvant chemotherapy identifies actionable therapeutic targets. Cancer Discov 4: 232-245, 2014. 
43. Ozretic P, Alvir I, Sarcevic B, Vujaskovic Z, Rendic-Miocevic Z Roguljic A and Beketic-Oreskovic L: Apoptosis regulator Bcl-2 is an independent prognostic marker for worse overall survival in triple-negative breast cancer patients. Int J Biol Markers 33: $109-115,2018$.

44. Inuzuka H, Shaik S, Onoyama I, Gao D, Tseng A, Maser RS Zhai B, Wan L, Gutierrez A, Lau AW, et al: SCF(FBW7) regulates cellular apoptosis by targeting MCL1 for ubiquitylation and destruction. Nature 471: 104-109, 2011.

45. Wertz IE, Kusam S, Lam C, Okamoto T, Sandoval W, Anderson DJ, Helgason E, Ernst JA, Eby M, Liu J, et al: Sensitivity to antitubulin chemotherapeutics is regulated by MCL1 and FBW7. Nature 471: 110-114, 2011.

46. Leverson JD, Zhang H, Chen J, Tahir SK, Phillips DC, Xue J, Nimmer P, Jin S, Smith M, Xiao Y, et al: Potent and selective small-molecule MCL-1 inhibitors demonstrate on-target cancer cell killing activity as single agents and in combination with ABT-263 (navitoclax). Cell Death Dis 6: e1590, 2015.
47. Pan R, Ruvolo VR, Wei J, Konopleva M, Reed JC, Pellecchia M, Andreeff $M$ and Ruvolo PP: Inhibition of Mcl-1 with the pan-Bcl-2 family inhibitor (-)BI97D6 overcomes ABT-737 resistance in acute myeloid leukemia. Blood 126: 363-372, 2015.

48. Mojsa B, Lassot I and Desagher S: Mcl-1 ubiquitination: Unique regulation of an essential survival protein. Cells 3: 418-437, 2014.

49. Goldie H, Walker M, Graham T and Williams F: Topical effect of acriflavine compounds on growth and spread of malignant cells. J Natl Cancer Inst 23: 841-855, 1959.

50. Hassan S, Laryea D, Mahteme H, Felth J, Fryknas M, Fayad W, Linder S, Rickardson L, Gullbo J, Graf W, et al: Novel activity of acriflavine against colorectal cancer tumor cells. Cancer Sci 102: 2206-2213, 2011.

51. Kim SG, Kim CW, Ahn ET, Lee KY,Hong EK, Yoo BI and Han YB: Enhanced anti-tumour effects of acriflavine in combination with guanosine in mice. J Pharm Pharmacol 49: 216-222, 1997.

c) (i) $(9)$ This work is licensed under a Creative Commons

c) Attribution-NonCommercial-NoDerivatives 4.0 International (CC BY-NC-ND 4.0) License. 